\title{
Accuration Insertion Lma with Video Laryngoscope Compare with Classic Technique
}

\author{
Made Wiryana ${ }^{1}$, AAJ Van Zundert ${ }^{2}$, Ketut Sinardja ${ }^{3}$, Tjokorda Gde Agung Senapathi ${ }^{4}$, I Gusti Ngurah Mahaalit Aribawa ${ }^{5}$, I \\ Gusti Putu Sukrana Sidemen ${ }^{6}$ and Doddy Timboel Soedarso ${ }^{7^{*}}$ \\ ${ }^{1}$ Professor, Department of Anesthesiology, Pain Management and Intensive Care, Udayana University, Sanglah General Hospital, Denpasar-Bali, Indonesia \\ ${ }^{2}$ Professor of Anaesthesiology, University of Queensland \& Royal Brisbane and Women's Hospital, Brisbane, QLD, Australia \\ 34,5,6 Senior Lecturer, Department of Anesthesiology, Pain Management and Intensive Care, Udayana University, Sanglah General Hospital, Denpasar-Bali, \\ Indonesia
}

${ }^{7}$ Resident, Department of Anesthesiology, Pain Management and Intensive Care, Udayana University, Sanglah General Hospital, Denpasar-Bali, Indonesia

Received: April 13, 2017; Accepted: June 02, 2017; Published: June 21, 2017

*Corresponding author: R. Doddy Timboel Soedarso, Resident, Department of Anesthesiology, Pain Management and Intensive Care, Udayana University, Sanglah General Hospital, Denpasar-Bali, Indonesia, E-mail: doddy.docotor@gmail.com

\begin{abstract}
Background: Laryngeal Mask Airways (LMA) is often performed for airway management. Many insertion techniques of supraglottic airway devices have been described in an attempt to obtain an accurately-positioned and a well-functioning airway. The classic insertion technique, as advised by the manufacturers is frequently used, but this insertion is usually blind without knowing whether the mask sits perfectly, and is often left in position as long as adequate ventilation of the lungs is achieved.
\end{abstract}

Methods: In this double-blind randomized controlled trial, the study subjects (total 106 patients) were divided into two groups, using either videolaryngoscopy-guided or classic blind insertion techniques. The study compared the accuracy of the LMA position based on the Fiberoptic Laryngeal Score (FLS), the clinical score, the number of insertion attempts of the LMA and complications such as a sore throat and blood on the LMA cuff.

Result: Correct insertion of the LMA by videolaryngoscope was significantly higher than the use of the classic blind insertion technique based on FLS assessment $(79.2 \%$ vs $17 \%, \mathrm{p}<0.05)$ and clinical score $(100 \%$ vs $88.7 \%, \mathrm{p}<0.05)$.

The first attempt success insertion rate of LMAs was significantly higher superior in the group using videolaryngoscopy $(100 \%$ vs $88.7 \%, \mathrm{p}<0.05$ ).

The incidence of sore throat was not statistically significantly different, while for the incidence of blood present on LMA cuffs obtained statistically significant with $p$ value 0.028 .

Conclusion: Videolaryngoscop is a useful tool for insertion and guiding the LMA in a correct position. The camera on the tip of the video laryngoscope blade provides a wider angle view than that obtained with classic laryngoscopes, and thus we can place LMA in front of the vocal cords more easily.

Keywords: Laryngeal Mask Airway; Accurate Insertion Technique; Videolaryngoscope; Classic Insertion Technique

\section{Introduction}

The classic Laryngeal Mask Airway (LMA) (Teleflex, Athlone Co. Westmeath, Ireland) is often performed for airway management and is considered an easy-to-insert technique. However, failure with this insertion technique has often occurred in several studies, making immediate identification and correction of malpositioned devices necessary, to prevent complications [1].

Recently, studies focused on the position accuracy of LMAs by comparing device insertion using either a vision-guided insertion technique (with the help of a videolaryngoscope) or classic blind insertion techniques.

The advantage of using a videolaryngoscope as a guiding tool for LMA insertion is the presence of a camera on its blade that provides a $60^{\circ}$ wide angle of view compared to the $15^{\circ}$ angle of view with a standard laryngoscope blade [2]. The digital camera and light source (producing LED light) are mounted very close $(2-3 \mathrm{~cm})$ to the tip of the videolaryngoscope and close to the larynx [3]. The obtained viewpoint is closer to the glottis, which allows optimal insertion of the LMA and correction of any malposition much easier [2,4]. With classic laryngoscopy, the distance between the vocal cords and the laryngoscopist's eye is substantial $(30-40 \mathrm{~cm})$.

The purpose of this study was to obtain an optimal LMA placement so that the device could function properly.

\section{Materials and methods}

After approval of the study by the Ethical Committee of sanglah Hospital, University of Udayana Indonesia (plus number) and written informed consent of all subjects, the study subjects were divided into two groups to receive an LMA-Classic for airway management during general anesthesia with either a vision-guided (videolaryngoscope) or a blind (classic) insertion technique. 
This double-blind randomized control trial study included all patient underwent surgery under general anesthesi with LMA. Patients were excluded if the patient refused, patient had hipovolemic shock, patient with coronary hearth disease pregnant, physical status ASA 4,5 and 6, patient with complication with LMA insertion.

Each LMA-Classic was tested for cuff leakage whereby the choice of the device size depended on the patient's weight according to manufacturing specifications. All devices were fully deflated and prepared before use with a lubricant applied at the back of the cuff.

After induction, the videolaryngoscope (C-MAC@, Karl Storz Tuttlingen, and Germany) with a size 3 or 4 blade was carefully inserted in the valecula under direct vision. This allowed lifting of the epiglottis and using indirect vision of the video monitor screen to put the LMA in the correct position in the hypopharynx, with its distal cuff sitting in the entrance of the esophagus. Once the cuff of the LMA was positioned just below the epiglottis, the cuff was inflated till an adequate seal was obtained with as endpoint adequate alignment of the tip of the epiglottis with the tip of the rim of the proximal cuff of the LMA [5]. Subsequently, the videolaryngoscope was removed, the LMA connected to the breathing circuit and the intracuff pressure measured, whereby a cuff pressure of 40-60 cm H20 was considered to be adequate. Both a clinical score (Table 1) and the position of the LMA was evaluated with a fiberoptic laryngeal score (Table 2). Airway trauma was noted after removal of the device at the end of the operation and sore throat was evaluated in the recovery 2 hrs after the end of the operation, while the

\begin{tabular}{|l|l|}
\hline \multicolumn{2}{|l|}{ Table 1: Clinical score. } \\
\hline Score & Clinical \\
\hline 3 & Can ventilate \\
\hline 2 & Can ventilate with leakage \\
\hline 1 & Cannot ventilate \\
\hline
\end{tabular}

\begin{tabular}{|l|l|}
\hline \multicolumn{2}{|l|}{ Table 2: Fiberoptic laryngeal score. } \\
\hline Score & Laryngeal view \\
\hline 4 & Only vocal cord visible \\
\hline 3 & Vocal cord plus posterior epiglottis visible \\
\hline 2 & Vocal cords plus anterior epiglottis visble \\
\hline 1 & Vocal cord not visible \\
\hline (Brimacombe J, dkk, et al) [6].
\end{tabular}

Sampling for the number of samples in this study used hypothesis test with two proportions, with $90 \%$ power then obtained 106 samples, each 53 participants. $\mathrm{P}<0.05$ was considered as statistically significant. This statistical program with program SPSS vesion 20, IBM Armonk, NY, USA

$$
\mathrm{n}_{1}=\mathrm{n}_{2}=\frac{\left[\mathrm{Z} \alpha \sqrt{2 \mathrm{PQ}}+\mathrm{Z} \beta \sqrt{\mathrm{P}_{1} \mathrm{Q}_{1}+\mathrm{P}_{2} \mathrm{Q}_{2}}\right]^{2}}{\left(\mathrm{P}_{1}-\mathrm{P}_{2}\right)}
$$

Information: $\mathrm{n} 1=\mathrm{n} 2=$ number of samples for one group; $\mathrm{Z} \alpha=\mathrm{Z}$ value for certain $\alpha ; \mathrm{Z} \beta=\mathrm{Z}$ value for certain power (1- $\beta$ ); $\mathrm{P}_{1}=$ the proportion of accuracy in the laryngoscope video; $\mathrm{P}_{2}=$ Proportion of accuracy on the classical way.

\section{Results}

Patients' characteristics (age, gender, body mass index (BMI) and ASA) were normally distributed and considered homogenous with no differences between the two groups $(\mathrm{p}>$ 0.05), (Table 3).

\begin{tabular}{|c|c|c|c|}
\hline & Technique & ertion & \\
\hline Characteristics & $\begin{array}{c}\text { Video } \\
\text { Laryngoscope } \\
(n=53)\end{array}$ & $\begin{array}{c}\text { Classic } \\
(\mathrm{n}=44)\end{array}$ & $\mathrm{p}$ \\
\hline Age (year), mean + SD & $37.3 \pm 16.4$ & $36.8 \pm 15,8$ & 0.857 \\
\hline $\begin{array}{l}\text { Gender } \\
\text { Male } \\
\text { Female }\end{array}$ & $\begin{array}{l}25(47.2) \\
28(52.8)\end{array}$ & $\begin{array}{l}25(47.2) \\
28(52,8)\end{array}$ & 1.000 \\
\hline BMI $\left(\mathrm{kg} / \mathrm{m}^{2}\right)$, mean $+\mathrm{SD}$ & $21.9 \pm 3.5$ & $22.1 \pm 3.4$ & 0.688 \\
\hline $\begin{array}{r}\text { ASA } \\
1 \\
2 \\
3\end{array}$ & $\begin{array}{c}32(60.4) \\
16(30.2) \\
5(9.4)\end{array}$ & $\begin{array}{c}29(56.7) \\
19(35.8) \\
5(9.4)\end{array}$ & 0.817 \\
\hline
\end{tabular}

The results were presented in mean $( \pm=S D)$ or ratio (\%); $p>0.05$ was considered normal distribution of data.

Fiberoptic laryngeal score FLS assessment classifies into 2 groups that are accurate and less accurate. FLS score 4 is the group accurate while score 3 , score 2 and score 1 are the grops less accurate. In this study we did not found FLS with score 1.

In the videolaryngoscope group ( $\mathrm{N}=53$ patients), 42 (79.2\%) LMAs were positioned accurately and 11 (20.8\%) were in a substandard position. When the classical blind techniques were used ( $\mathrm{N}=53$ patients), only $9(17 \%)$ LMAs were positioned accurately and $44(83 \%)$ were malpositioned. Test analysis comparison of proportion in order to compare the proportion of proper insertion based research group that is shown in the cross tabulation (Table 4). Based on the FLS assessment, relative risk is 4.7 , it is mean insertion using videolaryngoscopy is 4.7 times more accurate ( $p$ 0.001) resulting in an optimal position than using classic technique based on the clinical score assessment of accuracy of LMA insertion (Table 5), all patients in the videolaryngoscope group earned score 1 , while with the classical technique 47 (88.7\%) earned score 1 and 6 (11.3\%) earned score $2(\mathrm{p}=0.05)$.

All 53 patients (100\%) in the videolaryngoscope group required only one-attempt insertion (Table 6). In the classic 
technique group, one-attempt successful insertion was obtained in 47 patients (88.7\%), second-attempt insertion required by whereas in 5 patients (9.4\%) a second attempt and in one patient $(1.9 \%)$ a third-attempt was needed $(\mathrm{P}<0.05)$.

Table 7 shows data on trauma of the airway (sore throat and blood presence on cuff). No complications were seen in the videolaryngoscope group, whereas in the classic technique 1 patient $(1.9 \%)$ had sore throat and $5(9.4 \%)$ had blood on the

\begin{tabular}{|c|c|c|c|c|c|}
\hline \multirow{2}{*}{$\begin{array}{l}\text { Variable insertion } \\
\text { teqnique }\end{array}$} & \multicolumn{2}{|c|}{ Accuracy } & \multirow[b]{2}{*}{$\mathrm{RR}$} & \multirow{2}{*}{$\begin{array}{c}95 \% \\
\text { Convidence } \\
\text { interval }\end{array}$} & \multirow[b]{2}{*}{$\mathrm{p}$-value } \\
\hline & Accurate & $\begin{array}{c}\text { Less } \\
\text { accurate }\end{array}$ & & & \\
\hline $\begin{array}{l}\text { Video } \\
\text { laryngoscope }\end{array}$ & $42(79.2 \%)$ & $11(20.8 \%)$ & \multirow{2}{*}{4.7} & \multirow{2}{*}{$2.5-8.7$} & \multirow{2}{*}{$<0,001$} \\
\hline Classic insertion & $9(17.0 \%)$ & $44(83.0 \%)$ & & & \\
\hline
\end{tabular}

Statistic test with chi-squre test $\mathrm{p}<0.05$

Table 5: Comparative Analysis of Accuracy Insertion LMA based on clinical score

\begin{tabular}{|c|c|l|l|}
\multirow{2}{*}{$\begin{array}{c}\text { Insertion LMA } \\
\text { technique }\end{array}$} & \multicolumn{2}{|c|}{ Clinical score } & \multirow{2}{*}{ P } \\
\cline { 2 - 3 } & 1 & 2 & \\
\hline $\begin{array}{c}\text { Video } \\
\text { laryngoscope }\end{array}$ & $53(100 \%)$ & $0(0 \%)$ & 0.013 \\
\hline Clasic insertion & $47(88.7 \%)$ & $6(11.3 \%)$ & \\
\hline
\end{tabular}

Table 6. Comparison of total insertion LMA using video laryngoscope with Classical Technique

\begin{tabular}{l|c|c|c|c|}
\multirow{2}{*}{$\begin{array}{l}\text { Insertion LMA } \\
\text { technique }\end{array}$} & \multicolumn{3}{|c|}{ Total insertion } & \multirow{2}{*}{$\mathrm{p}$} \\
\cline { 2 - 4 } & 1 & 2 & 3 & \\
\hline Video laryngoscope & $53(100 \%)$ & $0(0 \%)$ & $0(0 \%)$ & 0.042 \\
\hline Classic insertion & $47(88.7 \%)$ & $5(9.4 \%)$ & $1(1.9 \%)$ & \\
\hline
\end{tabular}

Table 7. Complications Comparison based on LMA insertion technique

\begin{tabular}{|c|c|c|c|}
\hline \multirow[t]{2}{*}{ Complication } & \multicolumn{2}{|c|}{ LMA Insertion technique } & \multirow[b]{2}{*}{$\mathrm{p}$} \\
\hline & $\begin{array}{c}\text { Video } \\
\text { laringoscope }\end{array}$ & Classic & \\
\hline Sore throat & $0(0) \%$ & $1(1,9 \%)$ & 0.5 \\
\hline $\begin{array}{l}\text { Blood on the cuff of the } \\
\text { LMA }\end{array}$ & $0(0 \%)$ & $5(9.4 \%)$ & 0.028 \\
\hline
\end{tabular}

\section{Discussion}

Vision-guided insertion of LMA using videolaryngoscopy, offers signifant advantages over classic insertion techniques, as it avoids the "blind" insertion of the airway device, which most often results in inadequate positioning and all its complications on airway exchange, including leak and obstructive airways. With the presence of the camera tip on the videolaryngoscope blade, a wide angle of view allows to see clearly what happens during insertion of the LMA. All malpositioned LMAs can immediately be reversed using correcting manoeuvres which usually consist of lifting the jaw, creating more space between the back of the tongue and the posterior pharyngeal wall, lifting the epiglottis further away from the posterior wall. This manoeuvre corrects any epiglottis down folding. Furthermore, one can visualize the airway device sitting in the hypo pharynx, with its distal cuff in the opening of the esophagus, and the epiglottis resting on the outside of the proximal cuff, aligning both ends to each other. The latter proofs that the correct size of the LMA device is used. If there is no alignment between the tip of the epiglottis and the rim of the inflated proximal cuff, there is a strong possibility that the tube opening is not opposed to the trachea inlet, again potentially resulting in inadequate airway exchange and airway leaks. The position of the LMA is the most important part that needs to be checked as more than $75 \%$ of all inserted laryngeal masks are positioned incorrectly with the epiglottis in the bowl of the device. As long as there is no full downfolding of the epiglottis in the bowl of the LMA with full obstruction of the device, clinically the device can still produce an adequate although suboptimal airway. In case of a massive leak (due to e.g. distal tip folding over backwards, distal tip sitting in between and across the vocal cords) or obstruction of the airway (due to a large downfolding of the epiglottis obstructing completely the tracheal inlet and the LMA tube) correction is needed imminently, with either the use of a videolaryngoscope or withdrawing the LMA altogether. Fibreoptic evaluation will reveal that the position is not correct, but does not allow any corrective manoeuvres. If videolaryngoscopy results in an adequate position of the LMA, there is no further need to use a (more costly) fibreoptic scope.

Therefore, correct positioning of an adequately sized LMA using vision-guided insertion technique, is the most important aspect to achieve an optimal functioning of the airway during general anaesthesia with a laryngeal mask. Oropharyngeal leak pressure, intracuff pressure, type of brand, whether or not an inflatable cuff is present and even sizing of the LMA are secondary to optimal position. Without an optimal position of the LMA, all the other parameters do not mean anything.

This obtained viewpoint closer to the glottis, which is expected that we can put LMA in front of the vocal cords easier $[2,3]$.

Each participant in our study received the LMA-Classic with size adjusted by weight and the cuff fully deflated. This treatment is in accordance with earlier research from Jiwon An, et al. [6] comparing fully and partially deflated LMA, resulting in a more accurate method if the cuff was fully deflated [7].

Choo, et al. [7] compared the position of the LMA-Flexible in 108 patients undergoing dental surgery using either a 
standard laryngoscope or the classic 'blind' insertion technique. In all cases, FLS was used to check the positioning of the LMA FLS grade 4 was obtained in 32 patients $(59.3 \%)$ with the classic standard laryngoscope, while 20 patients (37\%) In 108 patients gained 32 patients $(59.3 \%)$ with FLS 4 on classic laryngoscopes, while 20 patients (37\%) showed a FLS grade 4 with classic 'blind' insertion techniques of the LMA. Choo et al. too confirmed that the use of a standard laryngoscope can help in placing the LMA in a better position, although the use of a videolaryngoscope resulted in a higher success rate for the accuracy of the position of the LMA [8].

Ramachandran et al, [9] studied 15.795 cases whereby an LMA was inserted and studied the complications related to non-optimal positioning. 170 patients experienced airway problems. More than $60 \%$ patients with lma had failure experienced significant hypoxia, hypercapnia or airway obstruction whereas $42 \%$ presented with inadequate ventilation related to leak.

It should be noted that a high LMA cuff pressure can cause a postoperative sore throat [9]. Both over inflation (compromise mucosal blood flow) and under inflation (risk for aspiration of gastric content) should be avoided aiming for an intracuff pressure of $40-60 \mathrm{~cm} \mathrm{H}_{2} 0$.

Limitations of this study include: a) researchers did not monitor the duration and severity score of airway trauma, nor the pain intensity; b) the LMA-Classic was used as the standard airway device - we need to verify whether this also applies to other airway devices, not included in this study.

\section{Conclusion}

Vision-guided insertion of the LMA, using videolaryngoscopy, contrary to a "blind" insertion, provides more accurate information of LMA positioning, contributing to a more optimal positioned device in the hypopharynx, resulting in better airway exchange, less airway trauma, and contributing to the overall safety of patients.

\section{References}

1. Bimia Shama, Javashee Sood, Chand Sahai, V. P. Kumra. Troubleshooting Proseal LMA. Indian J Anaesth. 2009;53(4):414-424.

2. Van Zundert AA, Kumar CM, Van Zundert TC. Malpositiong of supraglottic airway devices: Preventive and corrective strategies. Br J Anaesth. 2016;116(5):579-582. doi: 10.1093/bja/aew104

3. Van Zundert A, Pieters B, Doerges V, Gatt S. Videolaryngoscopy allows a better view of the pharynx and larynx than classic laryngoscopy. $\mathrm{Br} \mathrm{J}$ Anaesth. 2012;109(6):1014-1015. doi: 10.1093/bja/aes418

4. Maassen R, Lee R, van Zundert A, Cooper R. The videolaryngoscope is less traumatic than the classic laryngoscope for difficult airway in an obese patient. J Anesth. 2009;23(3):445-448. doi: 10.1007/s00540009-0780-1

5. Van Zundert AAJ, Gatt SP, Kumar CM, van Zundert TCRV, Pandit JJ. 'Failed supraglottic airway': an algorithm for suboptimally placed supraglottic airway devices based on videolaryngoscopy. Br J Anaesth. 2017;118(5):645-649. doi: 10.1093/bja/aex093

6. Brimacombe J, Berry A. A proposed fiber-optic scoring system to stadardize the assesment of laryngeal mask airway position. Anesth Analg. 1993;76(2):457.

7. Jiwon An, Seo Kyung Shin, Ki Jun Kim. Larymgeal mask airway insertion in adults: Comparisson between fully deflated and partially inflated technique. Yonsei Med J. 2013;54(3):747-751.

8. Choo C.Y., Koay C.K. Yoong C.S. 2012. A randomised controlled trial comparing two insertion techniques for laryngeal Mask Airway flexible in patient undergoing dental surgery. Anaesthesia. 2012;67(9):986-990. doi: 10.1111/j.1365-2044.2012.07167.x

9. Ramachandran SK, Mathis MR, Tremper KK, Shanks AM, Kheterpal S. Predictor and clinical outcome from failed laryngeal laryngeal mask airway unique. Anesthesiology. 2012;116(6):1217-1226. doi: 10.1097/ALN.0b013e318255e6ab 